\title{
Musculoskeletal Pain in Hail Community: Medical and Epidemiology Study; Saudi Arabia
}

\author{
Prof. Safia Moussa ${ }^{1}$, Dr. Fatmah Al Zaylai ${ }^{2}$, Ahlam alomar ${ }^{3}$, Haneen AlOufi ${ }^{4}$, \\ Njoud ALNodali ${ }^{5}$, Rhmh Thif Allh Alshmmry ${ }^{6}$, Samiah Al-Enzy $^{7}$ \\ ${ }^{1}$ Professor, University of Hail, College of Medicine, Microbiology and Parasitology Department, Hail, Saudi Arabia \\ ${ }^{2}$ Teaching Assistant, University of Hail, College of Medicine, Family Medicine Department, Hail, Saudi Arabia \\ ${ }^{3,4,5,6,7}$ Forth year medical Students, University of Hail, College of Medicine, Hail, Saudi Arabia
}

\begin{abstract}
Background: Musculoskeletal pain (MSP) particularly back and neck pain are common in Western industrialized countries. Aim of the Study: the aim of the current study was to investigate the pattern, prevalence, risk factors, and knowledge of MSP among Hail community. Methods: The study included two sections, Medical section, and Survey section. The medical one included 100 patients selected from rheumatology outpatient clinic in King Khalid Hospital in Hail region, complaining of MSP. The survey section was conducted on 1000 participants. It was a cross-sectional study conducted through distribution of questionnaires. Results: The medical section of the study revealed that most of the patients had chronic pain with a percentage of (42\%). Low back pain and neck pain were the common sites affected (52\% \& 41\%) respectively. Many underlying diseases were associated with MSP. The most common disease was vitamin $D$ deficiency. The results of the survey demonstrated positive relation between MSP and sociodemographic data. Awareness of the participants was not satisfactory. The most common risk factor (wrong practice) incriminated in MSP in the current study was using computers or mobiles for long durations (96.47\%). In addition, $60.57 \%$ of cases were obese most of their lifetime. Conclusion: Overall, our study found very high prevalence of MSP among hail population. It was less common than that reported from industrialized countries. The reported associated factors and socio-medical consequences were similar to some parts of the world. $\underline{\text { Recommendations: }}$ the current study found very high prevalence of MSP among hail population that affecting the participants work, by missing out working days. So an appropriate exercise program has to be adopted so as to alleviate pain and suffering among groups like in schools, hospitals and other work areas.
\end{abstract}

Keywords: Musculoskeletal pain in Hail community: Medical and Epidemiology study; Saudi Arabia

\section{Introduction}

Musculoskeletal pain (MSP) particularly back and neck pain are common in Western industrialized countries. Approximately most of all people will have one or more episodes of back pain in the course of their lives, and about half of them will have one or more episodes of neck pain (Frymoyer; 1988 \& Kelsey; 1988). The majority of all episodes of back and neck pain disappear within few months, often with the help of rest, analgesics, and home exercise (Spitzer et al ; 1987).

The recurrence rate of back and neck pain is high and approximately most of the episodes are followed by relapses. (Frymoyer; 1988 \& Kelsey; 1988). Little is known about the relevant prognostic features of back and neck pain. Prognoses seem to worsen with the occurrence of radiating pain and with increasing number of relapses (Hull ;1982). Although back and neck pain are the most frequent disorders of the musculoskeletal system in general practice; there is no consensus about the management of these conditions (Turk ; 1984).Several Risk factors for MSP in various anatomical pain locations have been identified. Strongest and most consistent associations are found for occupational exposure, both physical and psychosocial (Felson al., 2000), In the health care workers, back and neck pain complains are unusually high (Durmus et al ; 2012) Almost half of the undergraduates reported MSP in at least one body site (Smith P\& Leggat ; 2007). and general psychosocial factors like stress, anxiety, mood/emotions, cognitive functioning and pain behavior (Miranda et al ; 2001) In addition, pain related fear (pain catastrophizing) and avoidance behavior appear to be an essential feature of development of a chronic problem for a substantial number of patients with muscle pain ( Vlaeyen ; 2000) . Many studies investigated the risk factors associated with low-back pain in as age, gender, positive parental history of treatment for low-back pain, psychosocial events, frequency of sports, and other factors (de Zwart et al 1987 \& Thorbjornsson et al 2000).

Diagnostic tests for MSP usually include CT, MRI, and nerve conduction $(\mathrm{R})$. While the treatment modalities are mainly ultrasound therapy, spinal manipulation, massage, physical therapy, etc. (Chong ; 2010). To our knowledge, there are some researches dealing with the topic of MSP in Saudi Arabia. However no sufficient studies about back and neck pain in Hail region .So, the aim of the current study was to investigate the pattern, prevalence, risk factors and knowledge of MSP among Hail community, Saudi Arabia.

\section{Material and Methods}

1. Medical section: 100 patients were selected from rheumatology outpatient clinic in King Khaled Hospital in Hail region, complaining of MSP. The study was conducted during the year of 2013. They were categorized according to: pattern, site of pain, underlying disease, associated symptoms, and residence. The results were analyzed.

2. Survey section: This is a cross-sectional study carried out on Hail community. The study was conducted during the year of 2014. Selection of the participants was done by 


\section{International Journal of Science and Research (IJSR) \\ ISSN (Online): 2319-7064 \\ Index Copernicus Value (2013): 6.14 | Impact Factor (2014): 5.611}

simple random sampling. A questionnaire with closeended questions was designed following an extensive review of the literature on knowledge and attitude of MSP .The questionnaire was developed in English and then translated to Arabic. A pilot study was conducted on a sample of 20 students to assess the reliability of the questionnaire and to check for ease and clarity of items. Questions that seemed difficult were then modified. The questionnaire consisted of Questions about Prevalence, knowledge, practice, Consequent effects, etiology, and risk factors of MSP. The researchers gave a brief explanation about the main aims of the study before distributing the questionnaires. 1000 participants received questionnaires that cover all aspects of the study. The questionnaire was distributed and recollected. Results were analyzed.

\section{Results}

\section{Medical section:}

The pattern of MSP among patients attended to the rheumatology outpatient clinic in King Khalid Hospital was represented in table (1). Most of the patients had chronic pain with a percentage of (42\%). Low back pain and neck pain were the common sites affected (52\% \& 41\%) respectively (table 2). Concerning the underlying diseases, vitamin D deficiency represented the main cause of MSP $(83 \%)$. Disc prolaps was diagnosed in $(38 \%)$ of the cases (table 3 ). $38 \%$ and $29 \%$ of the patients were complaining of numbness and radiating lower limb pain respectively as shown in table (4). Patients resident in urban area were found to have MSP more than those of rural area (table 5).

Table 1: Pattern of MSP among patients attended rheumatology outpatient clinic in King Khalid Hospital, Hail region, Saudi Arabia

\begin{tabular}{|c|c|c|}
\hline \multirow{2}{*}{$\begin{array}{c}\text { Pattern of back } \\
\text { pain }\end{array}$} & \multicolumn{2}{|c|}{ Total number of patients having back pain } \\
\cline { 2 - 3 } & No. & $\%$ \\
\hline Acute pain & 24 & $24 \%$ \\
\hline Sub acute pain & 34 & $34 \%$ \\
\hline Chronic pain & 42 & $42 \%$ \\
\hline
\end{tabular}

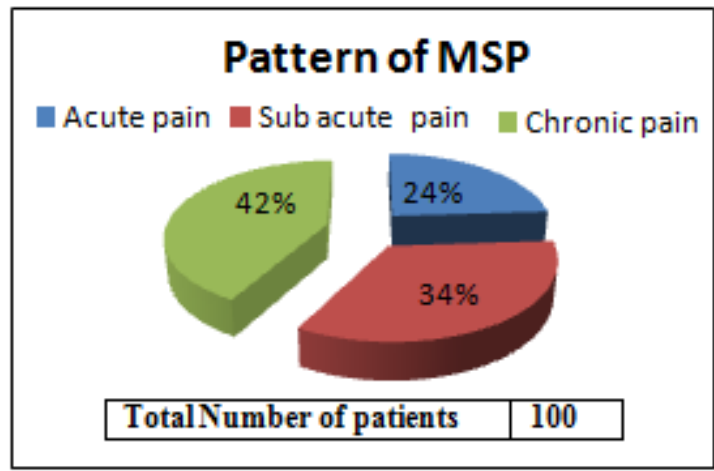

Table 2: Site of MSP among patients attended rheumatology outpatient clinic in King Khalid Hospital, Hail region, Saudi

Arabia

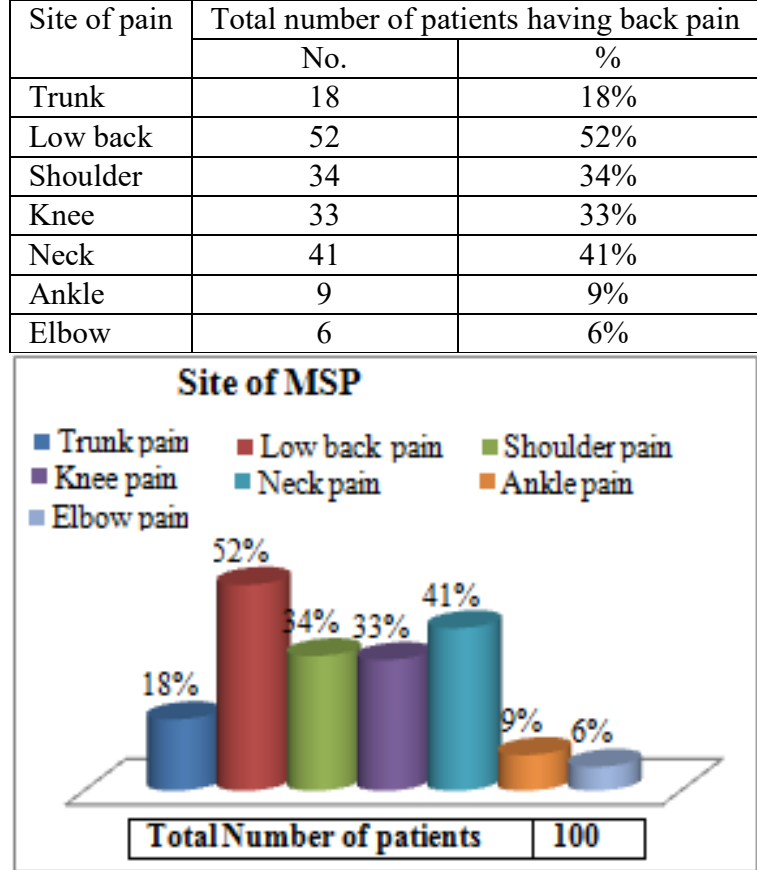

Table 3: Underlying diseases associated with MSP among patients attended rheumatology outpatient clinic in King Khalid Hospital, Hail region, Saudi Arabia

\begin{tabular}{|l|c|c|}
\hline \multirow{2}{*}{\multicolumn{1}{|c|}{ Associated Diseases }} & \multicolumn{2}{c|}{$\begin{array}{c}\text { Total number of } \\
\text { patients having back } \\
\text { pain }\end{array}$} \\
\cline { 2 - 3 } & No. & $\%$ \\
\hline Rheumatoid Arthritis & 9 & $9 \%$ \\
\hline Osteoarthritis and Degenerative changes & 33 & $33 \%$ \\
\hline Disc prolaps & 38 & $38 \%$ \\
\hline Mobile vertebrae & 12 & $12 \%$ \\
\hline Bone tumors & 7 & $7 \%$ \\
\hline Congenital narrowing of spinal canal & 19 & $19 \%$ \\
\hline Vitamin D deficiency & 83 & $83 \%$ \\
\hline Trauma and car accidents & 29 & $29 \%$ \\
\hline Ankylosing spondylitis & 1 & $1 \%$ \\
\hline
\end{tabular}

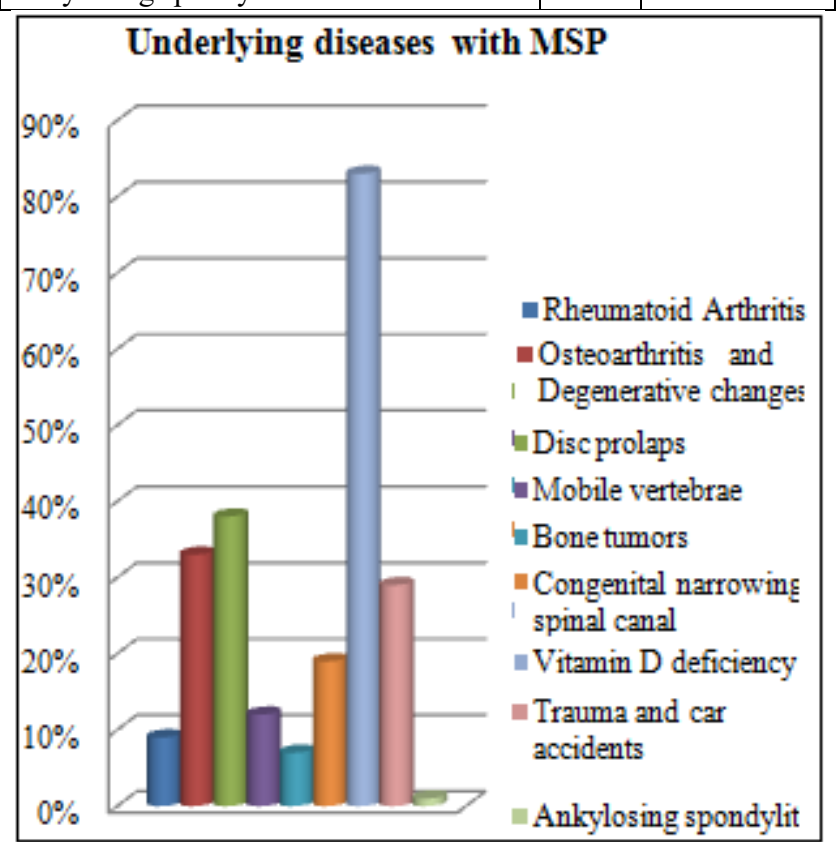




\section{International Journal of Science and Research (IJSR) \\ ISSN (Online): 2319-7064 \\ Index Copernicus Value (2013): 6.14 | Impact Factor (2014): 5.611}

Table 4: Associated symptoms with MSP among patients attended rheumatology outpatient clinic in King Khalid Hospital, Hail region, Saudi Arabia:

\begin{tabular}{|l|c|c|}
\hline \multirow{2}{*}{ Associated symptoms } & \multicolumn{2}{|c|}{ Total number of patients having MSP } \\
\cline { 2 - 3 } & No. & $\%$ \\
\hline Radiating lower limb Pain & 29 & $29 \%$ \\
\hline Numbness & 38 & $38 \%$ \\
\hline Pins sensation & 11 & $11 \%$ \\
\hline Muscle weakness & 15 & $15 \%$ \\
\hline Headache & 26 & $26 \%$ \\
\hline
\end{tabular}

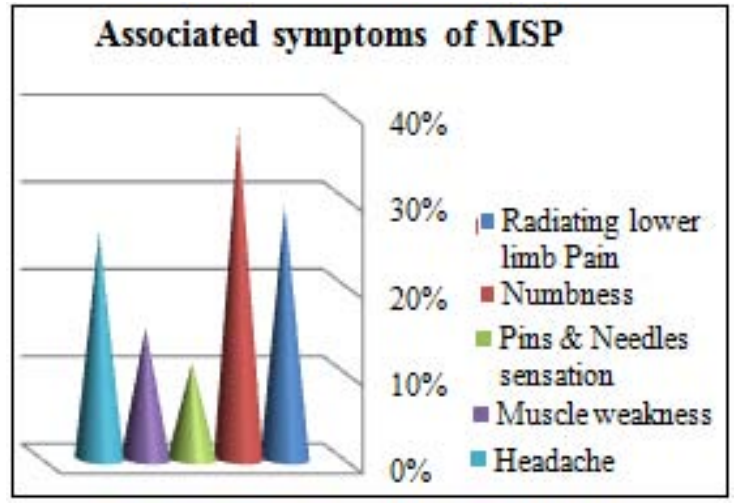

Table 5: Residence in relation to MSP among patients attended rheumatology outpatient clinic in King Khalid Hospital, Hail region, Saudi Arabia:

\begin{tabular}{|l|c|c|}
\hline \multirow{2}{*}{ Residence } & \multicolumn{2}{|c|}{ Total number of patients having back pain } \\
\cline { 2 - 3 } & No. & $\%$ \\
\hline Urban area & 68 & $68 \%$ \\
\hline Rural area & 32 & $32 \%$ \\
\hline
\end{tabular}

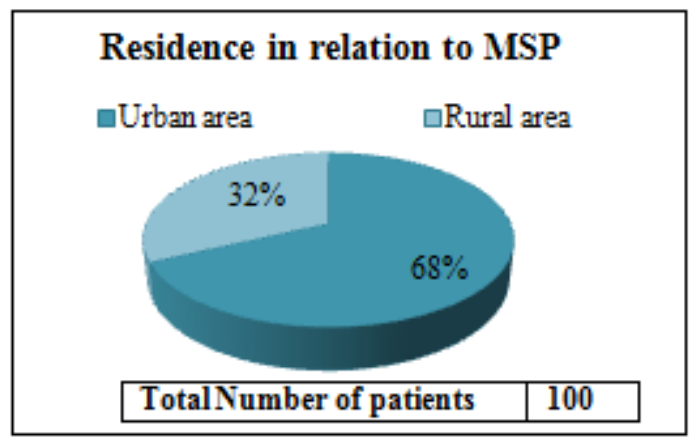

\section{The Survey Section}

A total of 1000 adults above age of 18 years old were included in the current study $(31.2 \%)$ of them were complaining of MSP during the period of the study.

Table (6) shows the relation of pain to age group. It shows that most of the cases are above the age of 50 years. The married women represented the majority of those with MSP. The highest rate of MSP was found among nurses followed by housewives $(48.7 \% \& 43.1 \%)$ respectively. (Tables 7,8 ) The knowledge of the participants in the present study is demonstrated in table (9).Most of the patients were aware by the fact that Lack of Physical exercise is an important cause of MSP $(88.9 \%)$, awareness about the role of osteoporosis and the use of computers and mobiles for long duration was not satisfactory $(23.6 \% \& 42.1 \%)$ respectively .

Sleeplessness was the main Consequent effects of MSP $(82.05 \%)$ revealed among the participants (table 10). The most common risk factor (wrong practice) incriminated in MSP in the current study was using computers or mobiles for long durations (96.47\%). Other cases gave histories carrying heavy objects, using non-medical mattresses $(88.46 \%)$ and sitting in wrong position $(84.9 \%)$. In addition , $60.57 \%$ of cases were obese most of their lifetime.(table 11) MSP was relieved mainly by using analgesics then by herbal preparation as shown in ( table 12).

Table 6: Prevalence of MSP in relation to Age in Hail community, Saudi Arabia:

\begin{tabular}{|c|c|c|c|}
\hline \multirow{2}{*}{ Age } & \multicolumn{2}{|c|}{$\begin{array}{c}\text { Number of participants having } \\
\text { pain }\end{array}$} & $\begin{array}{c}\text { Total } \\
\text { participants in } \\
\text { each age group }\end{array}$ \\
\cline { 2 - 3 } & No. & $\%$ & 188 \\
\hline $15-<20$ & 47 & $25 \%$ & 379 \\
\hline $20-<30$ & 88 & $23.2 \%$ & 238 \\
\hline $30-<40$ & 78 & $32.8 \%$ & 111 \\
\hline $40-<50$ & 42 & $37.8 \%$ & 84 \\
\hline$>50$ & 57 & $67.9 \%$ & \\
\hline
\end{tabular}

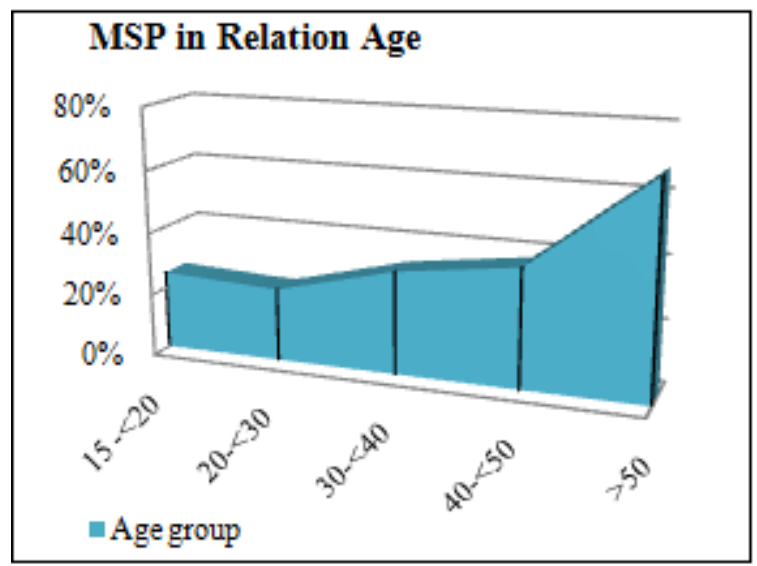

Total number of participants : 1000 participants with MSP : 312

Table 7: Prevalence of MSP in relation to marital status in Hail community, Saudi Arabia:

\begin{tabular}{|c|c|c|c|}
\hline \multirow{2}{*}{$\begin{array}{c}\text { Marital } \\
\text { status }\end{array}$} & \multicolumn{2}{|c|}{$\begin{array}{c}\text { Total number of } \\
\text { participants having pain }\end{array}$} & $\begin{array}{c}\text { Total cases according to } \\
\text { marital status }\end{array}$ \\
\cline { 2 - 3 } & No. & $\%$ & \\
\hline Single & 132 & $26.5 \%$ & 498 \\
\hline Married & 142 & $36.0 \%$ & 394 \\
\hline Divorced & 38 & $35.2 \%$ & 108 \\
\hline
\end{tabular}

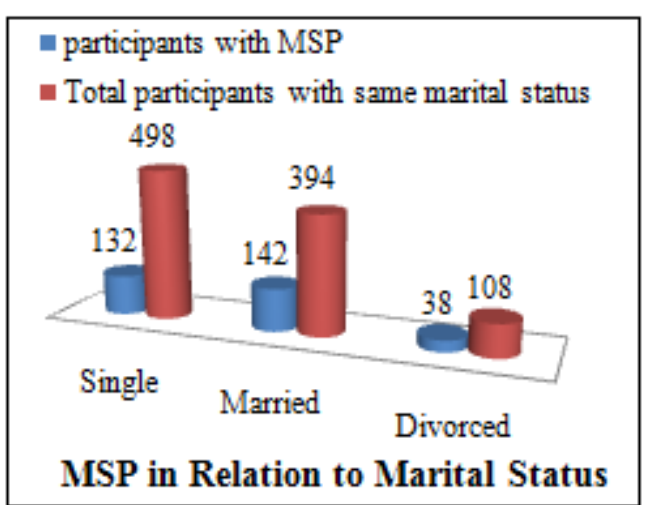




\section{International Journal of Science and Research (IJSR) \\ ISSN (Online): 2319-7064 \\ Index Copernicus Value (2013): 6.14 | Impact Factor (2014): 5.611}

Table 8: Prevalence of MSP in relation to occupation in Hail community, Saudi Arabia:

\begin{tabular}{|c|c|c|c|}
\hline Occupation & \multicolumn{2}{|c|}{$\begin{array}{c}\text { Total number of } \\
\text { participants having pain }\end{array}$} & $\begin{array}{c}\text { Total } \\
\text { participants }\end{array}$ \\
\cline { 2 - 3 } & No. & $\%$ & \\
\hline High school Students & 35 & $28.5 \%$ & 123 \\
\hline University students & 174 & $26.6 \%$ & 653 \\
\hline Nurses & 56 & $48.7 \%$ & 115 \\
\hline Housewives & 47 & $43.1 \%$ & 109 \\
\hline
\end{tabular}

\section{MSP in Relation to Occupation}

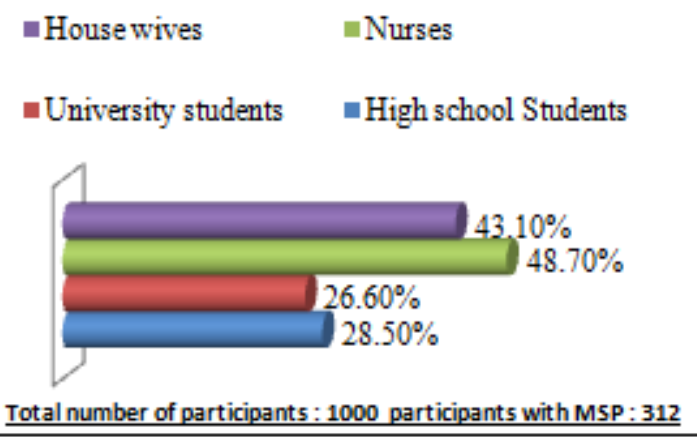

Table 9: Knowledge about MSP in Hail community, Saudi Arabia:

\begin{tabular}{|c|c|c|}
\hline \multirow{2}{*}{ Knowledge } & \multicolumn{2}{|c|}{$\begin{array}{c}\text { Participants } \\
\text { having } \\
\text { knowledge }\end{array}$} \\
\cline { 2 - 3 } & No. & $\%$ \\
\hline Unhealthy sitting position & 564 & $56.4 \%$ \\
\hline Carrying heavy objects & 679 & $67.9 \%$ \\
\hline Obesity & 528 & $52.8 \%$ \\
\hline Wearing high heel shoes & 341 & $34.1 \%$ \\
\hline Use of computers or mobiles for long & 421 & $42.1 \%$ \\
\hline duration & & \\
\hline Lelack of Physical exercise & 889 & $88.9 \%$ \\
\hline Relation of Trauma to back pain & 236 & $23.6 \%$ \\
\hline
\end{tabular}

Knowledge about MSP

Total number of participants: 1000
Table 10: Consequent effects and quality of life of patients with MSP, Hail region, Saudi Arabia:

\begin{tabular}{|c|c|c|}
\hline \multirow{2}{*}{ Consequent effects } & \multicolumn{2}{|c|}{$\begin{array}{c}\text { Participants having } \\
\text { pain }\end{array}$} \\
\cline { 2 - 3 } & No. & $\%$ \\
\hline Sleeplessness & 256 & $82.05 \%$ \\
\hline Nervousness & 241 & $77.24 \%$ \\
\hline Difficult daily work & 240 & $76.92 \%$ \\
\hline Difficult to prostrate during praying & 178 & $57.05 \%$ \\
\hline Inability to complete the household duties & 139 & $44.55 \%$ \\
\hline Inability to complete the working day & 290 & $77.9 \%$ \\
\hline
\end{tabular}

\section{Consequent effects with MSP Sleeplessness $_{\text {S }}$}

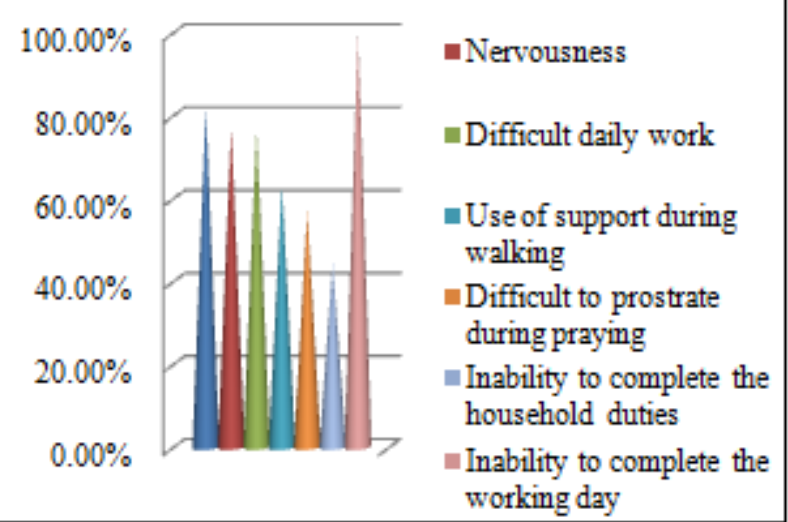

Total number of participants with MSP : 312

Table 11: Etiology and Risk factors (wrong practice )of MSP among Hail population, Saudi Arabia:

\begin{tabular}{|c|c|c|}
\hline Causes and risk factors & \multicolumn{2}{|c|}{$\begin{array}{c}\text { participants } \\
\text { having pain }\end{array}$} \\
\cline { 2 - 3 } & No. & $\%$ \\
\hline $\begin{array}{c}\text { I used to practice an Unhealthy sitting } \\
\text { position }\end{array}$ & 265 & $84.9 \%$ \\
\hline I always carry heavy objects & 231 & $74.03 \%$ \\
\hline I am overweight most of my lifetime & 189 & $60.57 \%$ \\
\hline $\begin{array}{c}\text { I like to wear high heel shoes } \\
\text { pillows }\end{array}$ & 136 & $43.58 \%$ \\
\hline $\begin{array}{c}\text { I don't use Medical mattresses and } \\
\text { duration }\end{array}$ & 276 & $88.46 \%$ \\
\hline $\begin{array}{c}\text { I use computers or mobiles for long } \\
\text { I don't practice Physical exercise }\end{array}$ & 301 & $96.47 \%$ \\
\hline I always have stress during daily life & 256 & $82.05 \%$ \\
\hline
\end{tabular}




\section{International Journal of Science and Research (IJSR) \\ ISSN (Online): 2319-7064}

Index Copernicus Value (2013): 6.14 | Impact Factor (2014): 5.611

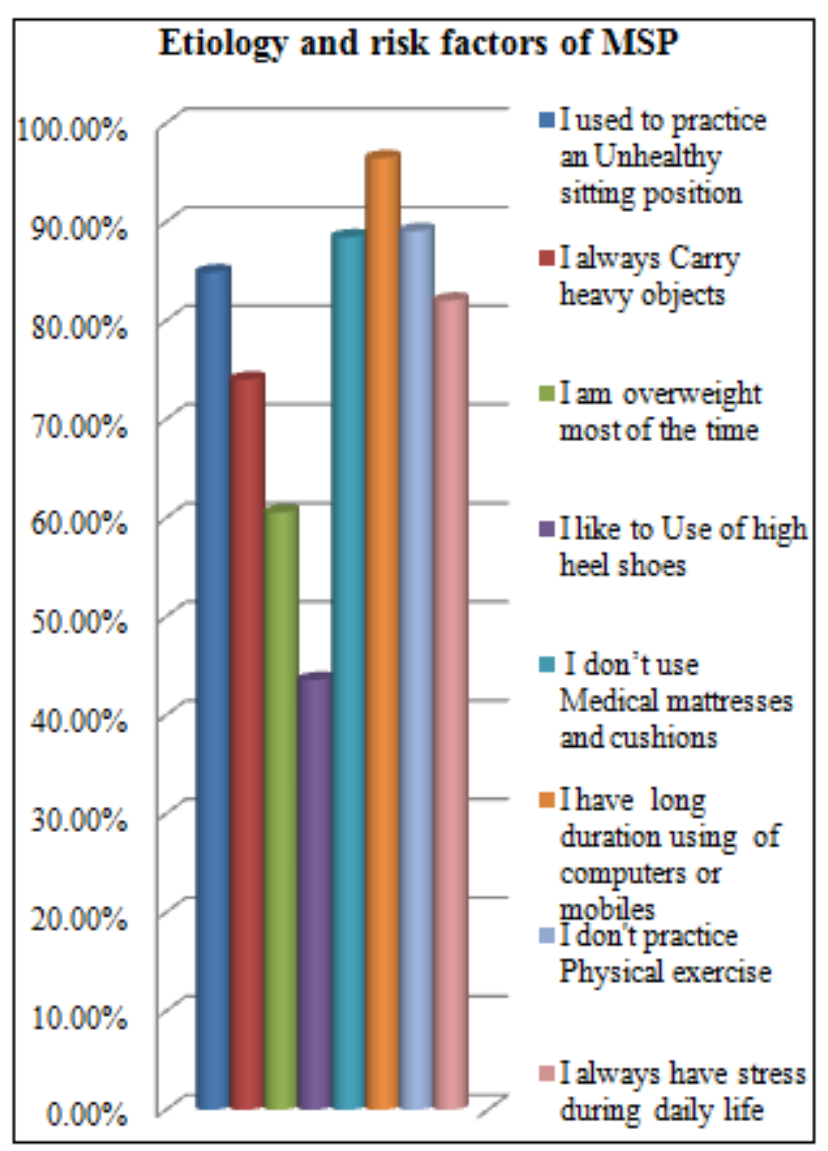

Total number of participants having musculoskeletal pain: 312

Table 12: Reliving factors of MSP among Hail population, Saudi Arabia :

\begin{tabular}{|c|c|c|}
\hline \multirow{2}{*}{ Reliving factors } & \multicolumn{2}{|c|}{ participants having pain } \\
\cline { 2 - 3 } & No. & $\%$ \\
\hline Chinese needles & 69 & $22.1 \%$ \\
\hline Physiotherapy & 201 & $64.4 \%$ \\
\hline Bed rest & 218 & $69.9 \%$ \\
\hline Analgesics & 277 & $88.7 \%$ \\
\hline Corticosteroids & 94 & $30.1 \%$ \\
\hline Herbal preparations & 269 & $86.2 \%$ \\
\hline
\end{tabular}

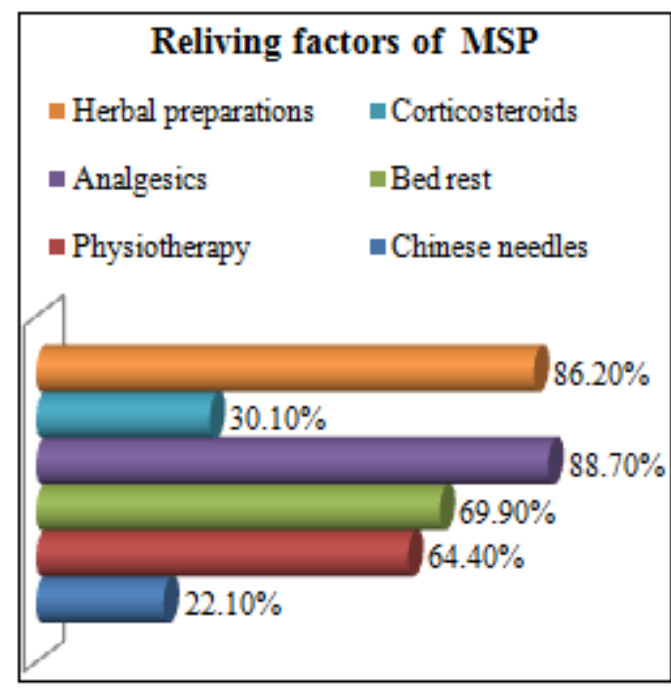

Total number of participants having musculoskeletal pain: 312

\section{Discussion}

Our findings showed that the prevalence of low back pain is $52 \%$, which is relatively high, compared to the previous studies. (Chiu ; 2007 , Darwish \&Zuhair 2013, Yue ; 2012. Jin ; 2004 ). Neck pain prevalence just followed the low back pain $(41 \%)$ and then shoulders pain (34\%), Mengestu and Zele ; 2014 found the same results, with a low back pain prevalence of $57.5 \%$. They noted that lack of physical exercise, provisions of office at work and satisfaction with working environment were the factors associated with high prevalence of low back pain among people (Mengestu and Zele ; 2014).

Our study also showed a lower prevalence of low-back pain compared to the study conducted by Darwish and Zuhair among secondary school teachers in the Eastern region of Saudi Arabia (68.2\% ) in which it is logic to find this results due to the nature of their participants' occupation which needs long standing throughout the teaching day (Darwish and Zuhair ;2013) .

Patient with neck pain in the current work were $41 \%$ which is lower than reported by others ( $56.8 \%$ reported by Yue ; 2012 .) and ( 69.3\%) was reported by Chiu in 2007. However similar results (42.1\% ) were obtained by Darwish. (Darwish and Zuhair ;2013) .

After low back pain, shoulder $34 \%$ and knee pain 33\% were the next most frequent site of MSP found in our study, which are considered higher compared to previous similar study,( Durmus \& Ilhanli ; 2012 ). Moreover, similar to the results on low back pain, we found significant associations of knee pain with the presence of a concomitant vitamin D deficiency (Tae-Hwan Kim et al ,; 2013) . On the contrarily , another study reported higher ratios of shoulder pain as $59.2 \%, 55.9 \%, 48.7 \%$ of their subjects . ( Yue in 2012, Durmus \& Ilhanli ; 2012.On the other hand, ankle pain was reported in the present study only in $9 \%$ of our cases which is much lower that of others ( Bergman et al ; 2001 ). Furthermore, the prevalence of elbow pain in the current study was very low $(6 \%)$ which is slightly less than both the study of Darwish (10.0\%) and Durmus (42\%).

The results of the present research revealed significant association between the high prevalence of MSP and many underlying disease like Vitamin D deficiency, Osteoarthritis , Degenerative changes, Disc prolapse, Mobile vertebrae, Congenital narrowing of spinal canal and Trauma and car accidents.

Some of the previous diseases were claimed by others to be associated (Elliot et al 1999) .However, whether these factors are truly Contributing the high prevalence of low back pain needs further studies .

The more prevalence of MSP in urban areas may be explained on the basis that most people have sitting jobs which is documented in the study of Hartvigsen et al who found direct association of MSP with sedentary office works .However this question was addressed in a recent critical review studies on the subject showing no clear association with sitting-at-work jobs ( Hartvigsen et al ; 2000) . 


\section{International Journal of Science and Research (IJSR) \\ ISSN (Online): 2319-7064 \\ Index Copernicus Value (2013): 6.14 | Impact Factor (2014): 5.611}

The current study revealed that the MSP pain is common. The prevalence among Hail population was found to be 31.2 $\%$. Similar result was found in Cuba (30.3\%).( Reyes et al ; 2000 ) . Likewise, in Thailand, similar prevalence of MSP was obtained $(36.2 \%)$ ( Chaiamnuary et al ' 1998). However, in India, the recorded prevalence of MSP pain among adults was lower $(18.2 \%)$ than ours .( Chopra ; 2002). On the other hand, a study carried out in Oman revealed back pain to be more prevalent in females with a percentage of (42\%). In addition higher rates were reported by other studies from both developed and developing countries (Hagen et al 1997 , Bergman et al ; 2001 , Reyes et al , 2000). In Norway, Hagen KB et al recorded a rate for MSP $57 \%$ of his participants respondents. ( Hagen et al 1997 ).The lower prevalence of MSP in the present study may be due to the younger ages of our participants than those reported from the West. (Hagen et al 1997 , Bergman et al ; 2001 , Reyes et al , 2000)

An additional reason may be the difference in methodology between our study and the others who used postal questionnaires or phone questionnaires. Moreover, another reason for the difference is the pattern and severity of MSP from region to region of the world, which was emphasized by 2 Swedish researches .( Bergman et al ; 2001, Anderson et al ' 1993 ) Furthermore, differences in the occurrence of MSP has been demonstrated among ethnically different groups of the same country. (Allison et al ; 2002)

In the present study, direct relationship was found between MSP and age, marital status and occupation. The prevalence increases with age reaching maximum above the age of 50 . This pattern with age has been reported by ( Bergman et al ; 2001).

Concerning sex, the results of the current work considered the prevalence in females as our study didn't include male participants. Studies among males in near region revealed a percentage of MSP to be lower in males (Pountain ; 1992 , Hagen et al 1997 , Bergman et al ; 2001). However, lack of association with sex has been reported by others. ( Elliot et al ; 1999). This can be explained on the basis of Hail citizens' nature, which is conservative, and it is not easy for women to seek medical advice .

Our study revealed an association between MSP and marital status. The highest rate of MSP was detected among married women followed by divorced while the least percentage was found among singles. Similarly, this relation was recorded by others.( Hagen et al 1997)

Concerning the occupation, the present study demonstrated a rate of MSP among nurses than others (48.7\%) followed by housewives $(43.1 \%)$. This high prevalence among both kind of population may be due to the nature of work of the nurse in which practicing many of unhealthy positions during dealing with patients. In addition, Housewives are facing many difficulties to practice any physical exercise being a part of this conservative community.

Most of the patients were aware by the fact that Lack of Physical exercise is an important cause of MSP (88.9\%) .However awareness about the role of osteoporosis and the use of computers and mobiles for long duration was not satisfactory $(23.6 \% \quad \& 42.1 \%)$ respectively. Knowledge obtained from participants in other Saudi areas varies from area to another (Darwish \&Zuhair 2013).

The most common risk factor (wrong practice) incriminated in MSP in the current study was using computers or mobiles for long durations $(96.47 \%)$. Other cases gave history of carrying heavy objects, using of non-medical mattresses $(88.46 \%)$ and sitting in wrong position $(84.9 \%)$. In addition, $60.57 \%$ of cases were obese most of their lifetime. Overweight has been thought to be associated with back pain, however, epidemiological studies showed both positive and negative relationship with back pain(Al-Shammari et al ,1994, Deyo et al , 1998 , Kuh et al , 1993).The association between obesity and back pain in our study is in agreement with the previous studies (Power et al ; 2001 , Kuh et al, 1993).That case control study utilizing patients attending primary care clinics in Riyadh, KSA found back pain to be more common in obese individuals.( Al-Shammari et al ,1994).Moreover, MSP was documented to be higher among school students because of the heavy bags lifting during school working days . (Darwish et al ; 2013 ) Use of nonmedical mattresses and pillows was also incriminated in causing MSP in many previous studies (Chaiamnuary et al ;1998 ).

MSP in the current research was relieved mainly by using analgesics which is logic but dangerous side effects have to be considered because Hail population are famous of using excessive amount of analgesic ( a notice during the hospital rounds) .Moreover, overuse of herbal preparation is very common in Hail community and there are experts in mixing herbs to relieve pain. However, it should be taken under medical supervision. Sleeplessness was the main consequent effects of MSP revealed among the participants in the current work. In addition most of the patients were not able to complete their working day, hence the cost effectiveness has to be evaluated.

\section{Conclusion}

Overall, our study found very high prevalence of MSP among hail population. It was less common than that reported from industrialized countries. The reported associated factors and socio-medical consequences were similar to some parts of the world.

\section{Recommendations}

Based on our study results, the high prevalence of MSP among hail population, which is affecting their work, by missing out working days and eventually affecting the hospital, cost effectiveness system as a whole should be considered. So, an appropriate exercise program has to be adopted so as to alleviate pain and suffering among groups like in schools, hospitals and other work areas. These programs could be incorporated into the curriculum of the school and university students by the Ministry of education of Saudi Arabia.

\section{Volume 4 Issue 11, November 2015}




\section{International Journal of Science and Research (IJSR)}

ISSN (Online): 2319-7064

Index Copernicus Value (2013): 6.14 | Impact Factor (2014): 5.611

\section{Limitation of the Study}

Although this study, included 1000 participants this sample is not considered enough to represent the whole Hail community, so in the future, it should extend to cover more areas of hail region specially the remote villages .

\section{References}

[1] Anderson HI, Ejlertsson G, Leden I, Rosenberg C. Chronic pain in a geographically defined general population: studies of differences in age, gender, social class, and pain localization. Clin J Pain 1993; 9: 174182.

[2] Al-Shammari S, Khoja T, Kremli M, Alballa S. Low back pain and obesity in primary health care, Riyadh, Saudi Arabia. Saud Med J 1994; 15: 223-226.

[3] Allison TR, Symmons DP, Brammah T, Haynes P, Rogers A, Roxby M, Urwin M. Musculoskeletal pain is more generalized among people from ethnic minorities than among white people in Greater Manchester. Ann Rheum Dis 2002;61:151-156.

[4] Bergman S, Herrstrom P, Hogstrom K, Peterson I, Svenson B, Jacobson L. Chronic musculoskeletal pain, prevalence rates and socio-demographic association in a Swedish population study. JRheumatol 2001; 28: 13691377.

[5] Chaiamnuary P, Darmawan J, Muirden KD, Assawatanabodee P.Epidemiology of rheumatic diseases in rural Thailand: aWHO-ILAR COPCORD study. Community-oriented programme for the control of rheumatic disease. J Rheumatol 1998; 25: 1382-1387.

[6] Chiu TT, Lam PK: The prevalence of \& risk factors for neck pain \& upper limb pain among secondary school teachers in Hong Kong. J Occup Rehabil. 2007;17:1932. DOI 10.1007/s 10926-006-9046-z.

[7] Chopra A, Saluja M, Patil J, Tandale HS. Pain and disability, perception and beliefs of a rural Indian population: A WHO-ILAR COPCORD Study, WHOInternational League of Associations for Rheumatology. Community Oriented Programme for Control of Rheumatic Diseases. J Rheumatol 2002; 29: 614-621.

[8] Chong EY. Subjective health complaints of teachers from primary \& secondary schools in Hong Kong. Int $\mathbf{J}$ Occup Saf Ergon. 2010;16:23-39.

[9] Durmus D, Ilhanli I. Are there work-related musculoskeletal problems among teachers in Samsun, Turkey? J Back Musculoskelet Rehabil. 2012;25:5-12. DOI:10.3233/BMR-2012-0304

[10]Darwish MA, Al-Zuhair SZ. Musculoskeletal pain disorders among secondary school Saudi female teachers. Pain Res Treat 2013; doi.org/10.1155/2013/878570.

[11] de Zwart BCH, Broersen JPJ, Frings-Dresen MHW, van Dijk FJH. Musculoskeletal complaints in the Netherlands in relation to age, gender and physically demanding work. Int Arch Occup Environ Health 1997;70:352-60. Eriksen W. The prevalenc

[12] Deyo R, Bass JE. Lifestyle and low back pain, the influence of smoking and obesity. Spine 1989; 14: 501506.
[13] Elliot AM, Smith BH, Penney KI, Smith WB, Chambers WA. The epidemiology of chronic pain in the community. Lancet 1999; 354: 1248-1252

[14] Frymoyer JW. Back pain and sciatica. N Engl JMed. 1988;318:291-300.

[15] Hagen KB, Bjorndal A, Uhlig T, Kvien TK. A population study of factors associated with general practitioner consultation for non-inflammatory musculoskeletal pain. Ann Rheum Dis 2000; 9: 788793.

[16]Hagen KB, Kvien TK, Bjorndal A. Musculoskeletal pain and quality of life in patients with noninflammatory joint pain compared to rheumatoid arthritis: a population survey. J Rheumatol 1997; 24: 1703-1709.

[17] Hartvigsen J, Leboeuf-Yde C, Lings S, Corder EH. Is sitting-while-at-work associated with low back pain? A systematic, critical literature review. Scand J Public Health 2000; 28: 230-239.

[18] Hull FM. Diagnosis and prognosis of low back pain in three countries. JR CON Gen Pract. 1982;32:352-356.

[19] Jin K, Sorock GS, Courtney TK. Prevalence of low back pain in three occupationalgroups in Shanghai, People's Republic of China. J Safety Res. 2004;35:2328.

[20] Jin-Oh Park, , Hak-Sun Kim, , and Seong-Hwan Moon, Prevalence of Vitamin D Deficiency in Patients with Lumbar Spinal Stenosis and its Relationship with Pain , Pain Physician 2013; 16:165-176 • ISSN 1533-3159

[21] Kelsey JL. Widemiology of Musculoskeletal Disorders. New York, NOxford

[22] Kuh DJL, Coggan D, Mann S, Cooper C, Yusuf E. Height, occupation and back pain in a national prospective study. Br J Rheumatol 1993; 32: 911-916

[23] Mengestu MY, Zele YT. Low back pain and associated factors among teachers in Gondar Town, North Gondar, Amhara Region, Ethiopia. Occ Med Health Affairs open access article. ISSN: 2329-6879. Accessed January 10, 2014.

[24] Miranda H, Viikari-Juntura E, Martikainen R, Takala EP, Riihimaki H. A prospective study of work related factors and physical exercise as predictors of shoulder pain. Occup Environ Med2001;58:528-34.

[25] Pountain G. Musculoskeletal pain in Omanis, and the relationship to joint mobility and body mass index. $\mathrm{Br} \mathrm{J}$ Rheumatol 1992; 31: 81-85.

[26] Power C, Frank J, Hertzman C, Schierhout G, Li L. Predictors of low back pain onset in a prospective British study. Am J Public Health 2001; 91: 1671-1678.

[27] Smith D. R. , and P. A. Leggat Prevalence and Distribution of Musculoskeletal Pain Among Australian Medical Students 2007, Vol. 15, No. 4 , Pages 39-46

[28] Spitzer WO, Leblanc FE, Dupuis M, eds. Scientific approach to the assessment andmanagement of activity related spinal disorders. Spine. 1987;7(suppl):I-59.

[29] Reyes Llerena GA, Guibert Toledars M, Hernandez Martinez AA, Gonzalez Otero ZA, Alcocer Varela J et al. Prevalence of musculoskeletal complaints and disability in Cuba. A community-based study using the COPCORD core questionnaire. Clin Exp Rheumatol 2000; 18: 739-742.

[30] Tae-Hwan Kim, , Byung Ho Lee, , Hwan-Mo Lee, Seung-Hwan Lee, 


\section{International Journal of Science and Research (IJSR) \\ ISSN (Online): 2319-7064}

Index Copernicus Value (2013): 6.14 | Impact Factor (2014): 5.611

[31] Thorbjornsson CB, Alfredsson L, Fredriksson K, Michelsen H, Punnett L, Vingard E, et al. Physical \& psychosocial factors related to low back pain during a 24-year period. A nested case control analysis. Spine. $2000 ; 25 ; 369-374$.

[32] Turk CT, Flor H. Etiological theories and treatments for chronic back pain, I: somatic models and interventions. Pain. 1984;19:105- 121. University Press Inc; 1982:145-167. Spitzer WO, Leblanc FE, Dupuis M, eds.Scientific approach to the assessment and management of activity related spinal disorders. Spine. 1987;7(suppl):I-59.

[33] Vlaeyen JW, Linton SJ. Fear-avoidance and its consequences in chronic musculoskeletal pain: a state of the art. Pain 2000;85:317-32.

[34] Yue P, Liu F, Li L. Neck/shoulder pain \& low back pain among school teachersin China, prevalence \& risk factors. BMC Public Health. 2012;12:789.

[35]Felson DT, Lawrence RC, Dieppe PA, Hirsch R, Helmick CG, Jordan JM, et al. Osteoarthritis: new insights. Part 1: the disease and its risk factors. Ann Intern Med 2000;133:635-46. 